\title{
TRAJETÓRIAS DO SABER FAZER DE UM ANTROPÓLOGO
}

\author{
Manuel Ferreira Lima Filho ${ }^{1}$
}

Em 1980, quando iniciei meus estudos no curso de Geologia, na região Amazônica, na Universidade Federal do Pará, iniciava, sem mesmo ter consciência na época, uma jornada de estranhamento e, ao mesmo tempo, um contínuo processo de conhecimento e de reflexões sobre as minhas e outras referências culturais pessoais, regionais, brasileiras. Longe de casa, dos meus, da minha cidade e do Centro Oeste, adentrei um mundo diferente, muitas vezes estranho, tantas outras fascinante, que me revelava, aos poucos, as impressões sobre o meu país, nossa gente, costumes e modos de conceber e agir.

$\mathrm{Na}$ Geologia, um curso notadamente marcado pela conexão da teoria com a pesquisa empírica de campo, que imputa ao aluno reflexões inclusive de cunho filosófico sobre nossas origens, sobre a evolução e, principalmente, saber lidar com as categorias tempo e espaço, embora numa grande escala, fui aprendendo a refletir sobre as disposições dos lugares, das evidências, das marcas. A frase que já me impressionava como noviço das ciências era a de que, na Geologia, o presente é a chave para o passado. Portanto, a interpretação seria o destino final do saber do geólogo. A ideia de interpretação, que eu aprenderia e ensinaria mais tarde, migraria para o campo das Ciências Sociais, de modo especial para a Antropologia interpretativa/compreensiva de Geertz, plasmada pela hermenêutica da Filosofia, a fim de compreender ou dar sentidos aos fenômenos sociais.

Estudei um período tardio da formação da terra, o Pleitoceno com suas últimas grandes mudanças climáticas. Nessa fatia analítica espaço-temporal, se encontra os primeiros movimentos dos hominídeos e suas distribuições culturais pesquisados por antropólogos físicos e arqueólogos, na tarefa nada fácil de montar o quebra-cabeça dos primeiros passos da humanidade. O problema, a pergunta, a busca constante por respostas passavam a ser procedimentos naturalizados na maneira de fazer pesquisa. Como condição inquestionável para produzir conhecimento, percebi que a Arqueologia precisava do diálogo interdisciplinar como, por exemplo, da Biologia, da Geografia, da Geofísica, da Geologia e da Antropologia Cultural. Eu também sorvia nas livrarias e bibliotecas as lições sobre os conceitos básicos dos estudos culturais, de maneira especial o viés teórico desenhado pela integração dos quatro campos, "four fields", da Antropologia norte-americana que induzia

\footnotetext{
${ }^{1}$ Universidade Federal de Goiás, Brasil.
} 
ao diálogo entre a Antropologia Física, Antropologia Cultural/Social, a Arqueologia e a Linguística. Organizava devagar a minha própria biblioteca: outro referencial da pesquisa que colava definitivamente em mim. Cresci ao redor de livros. Meu pai, formado em Letras Neolatinas era professor de Português e Latim e ensinava a mim e à minha irmã a classificar e guardar livros na enorme biblioteca que tínhamos em casa. Ali passei anos da minha vida estudando. Minha mãe, professora primária, nos ensinava o gosto pela ordem e estudos.

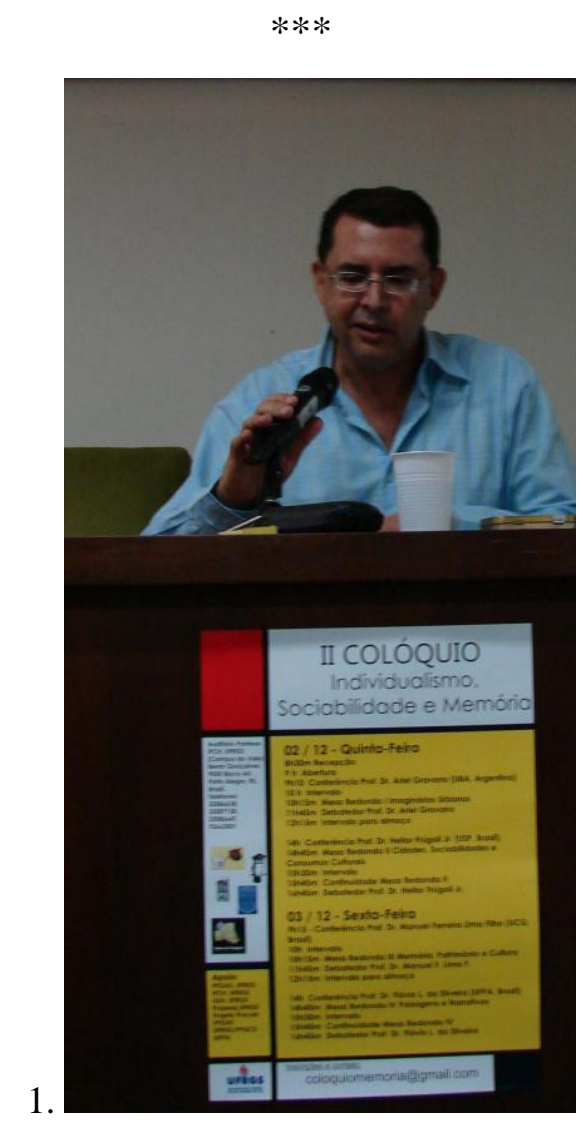

Prof. Manuel Ferreira Lima Filho. Foto de 03 dezembro 2010. Conferência no II Colóquio Individualismo, Sociabilidade e Memória. Sala Pantheon IFCH UFRGS. Acervo BIEV PPGAS IFCH UFRGS.

Então, fascinado pelo ofício de pesquisador - inclusive pelas viagens de campo busquei a sessão de Arqueologia coordenada pelo arqueólogo Mário Ferreira Simões do Museu Paraense Emílio Goedi fundada em 1871 em Belém. Estagiei durante dois meses, como voluntário e mais seis meses como bolsista de iniciação científica da SUDAM e depois um ano como bolsista de iniciação científica do CNPq. Tive, assim, acesso ao acervo das peças arqueológicas do Museu Goeldi, como a coleção dos muiraquitãs e as cerâmicas marajoaras e tapajônicas. Participei de uma primeira experiência de pesquisa arqueológica 
na região litorânea do Salgado paraense, num sítio-escola de "terra preta" e num "sítio sambaqui". Nesse tempo de estágio, tive contato pela primeira vez com uma exposição museológica na perspectiva etnológica, quando o etnobiólogo Darrell A. Posey desenvolveu uma exposição que destacava uma aldeia antiga e informações rituais, mitológicas e sociais dos Kaiapó. O mundo da pesquisa antropológica e suas conexões se abriam cada vez mais. No Museu Goeldi, a mesma instituição por onde haviam passado os etnólogos Curt Nimuendaju e Eduardo Galvão, eu respirava um cotidiano de pesquisas.

Ao terminar o curso de Geologia em 1985, já decidido a ingressar nos estudos de Antropologia/Arqueologia, voltei para Goiânia, minha cidade e cursei a Especialização em Antropologia Social no Museu Antropológico da Universidade Federal de Goiás.

Disputando uma vaga da "comunidade" me deparei com a questão do processo seletivo: por que fazer um curso de Antropologia vindo de uma formação da Hard Science? Respondi, então, que a formação sólida de Bronislaw Malinowski, como doutor em Ciências Matemáticas, afeiçoado ao pensamento lógico e à disciplina de reflexão, certamente o havia ajudado a formatar e sistematizar o método etnográfico, ou seja, explorar toda a potencialidade da coleta de dados via pesquisa de campo antropológica. Contextualizado historicamente e teoricamente o viés positivista e claramente evolucionista daquele autor quando a Antropologia se espelhava nos métodos classificatórios e comparativos da Biologia, Geografia e Geologia, o método etnográfico, esboçado por Franz Boas entre os Inuit, deve principalmente a Malinowski (1978), a sua gênese, sistematização e explicitação claras contidas na introdução de seu livro Os Argonautas do Pacífico Sul. Imerso na pesquisa de campo de longa duração, foi sua formação ampla e sólida, aliada à sua competência lingüística, que lhe deu plasticidade suficiente para modelar o método etnográfico, método que ajudaria a construir o ethos da própria Antropologia enquanto disciplina. Sem dúvida, a experiência e os escritos de Malinowski, inclusive seu diário de campo, publicado mais tarde por sua esposa, são um marco diacrítico na Antropologia. Numa tentativa de esboçar cinentificamente o conceito de cultura ele engenhou que essa seria resposta funcionais das estratégias humanas em atender suas necessidades vitais.

No curso de especialização fui aluno de Alcida Rita Ramos, Mireya Soares, Gustavo Lins Ribeiro, Leonardo Fígolli. Passei a refletir com as categorias de tempo e espaço no campo das Ciências Sociais. Fui apresentado a outras, como parentesco, território, corpo, desenvolvimento e gênero.

Como resultado desse percurso, tive o "Projeto Etnoarqueológico Karajá Ilha do Bananal" aprovado pelo CNPq para cursar o mestrado nos EUA. Ao mesmo tempo, 
ingressei na Universidade Católica de Goiás (UCG), por meio de seleção pública,. Na bancas estava o arqueólogo Pe. Pedro Ignácio Schmitz (UNISINOS). Era o ano de 1986.

Voltei para Amazônia, como pesquisador e professor do IGPA/UCG, para uma experiência de pesquisa internacional num sítio arqueológico na região de Santarém (PA), coordenada pela arqueóloga Anna $\mathrm{C}$. Roosevelt, às margens do rio Tapajós e do rio Amazonas. Ao voltar, refleti que precisava ainda de uma base teórica maior e mais fundamentada para enfrentar uma experiência de estudos no exterior. Além do mais, a rua onde eu nascera havia sido atingida pelo desastre radiológico do Césio 137. Da Amazônia vi estampados nos jornais amigos, meu próprio bairro e a rua onde nascera. Local em que ainda morava minha família. Vivi o impacto de um desastre ambiental, da inoperância das políticas públicas, da ineficácia dos agentes governamentais, e a manipulação dos dados, das estatísticas, das notícias e a obliteração do exercício pleno da cidadania em ter acesso à verdade. E ainda o preconceito por ser goianiense.

Dispensei a bolsa do CNPq e me candidatei ao mestrado em Antropologia Social da Universidade de Brasília, que daria de fato background à minha formação acadêmica, agora num ambiente de excelência, com ótima biblioteca, bolsa de estudos e colegas da pósgraduação. Adaptei o projeto da Ilha do Bananal para uma etnografia Karajá, sob a orientação do etnólogo Julio Cezar Melatti, uma vez que ele me convencera de que a etnografia dos Karajá estava por ser feita. O "Harvard Project Central Brazil” (Maybury Lewis (1979) dos anos 70, que reuniu etnólogos para mapear etnograficamente os grupos indígenas do Brasil Central, como David Maybury-Lewis (Xavante), Terence Turner (Kaiapó), Eleen Basso (Kuikuro), Julio C. Melatti (Krahó) e Roberto da Matta (Apinajé), não contemplara os Karajá. Como desafio, mergulhei nos estudos teóricos e etnográficos e realizei, em 1989/90, seis meses de pesquisa de campo entre os Karajá da aldeia Santa Izabel do Morro (TO). Escolhi o Hetohoky - um rito de iniciação masculina - nunca antes estudado, como fato social para entrar no complexo mundo social e cultural dos Karajá. Experimentei o método etnográfico em sua concepção clássica: fiz o mapa da aldeia medindo a passo duplo (que tanto havia praticado na graduação da Geologia) e tabulei populações e classes de idade. Numa planta baixa plotei as casas, a escola, o campo de futebol, o hospital indígena, a pista de avião, o rio, enfim, topografias etc. Levei dois meses em tal pleito e aos poucos fui construindo as genealogias, tecendo as casas e as parentelas na tramas do ritual e da vida social dos Karajá. O grupo não gostava de antropólogos. Era avesso a tantas políticas governamentais, visitas presidenciais (Getúlio Vargas e Juscelino Kubitschek) e à construção de um hotel turístico ao lado de sua aldeia. 
Alguns viviam tragados pela bebida alcoólica que disseram ter aprendido com a Fundação Brasil Central. Experimentei a densidade do encontro etnográfico: sua potencialidade de conhecimento sobre outra visão de vida tão singular e complexa, e ao mesmo tempo, a dramaticidade da construção da identidade indígena via processo desenvolvimentista (fronteira nacional). Fui adotado por uma família, recebi um nome e participei de todas as fases do ritual pela observação participante. Coletei amostras botânicas, uma ainda não classificada pela botânica ocidental e cuja classificação se deveu ao colega Heleno Dias do Departamento de Biologia da UFG; registrei espécies zoológicas e todas as fases do ritual com fotografias, tabelas, e anotações em cadernetas e diários de campo, além de inúmeras fitas gravadas e decupadas. Pude, nessa experiência de campo, aliar os meus conhecimentos da graduação, da especialização e do mestrado e produzir um texto. Consciente do poder que um texto tem em nossa sociedade e partindo do principio metodológico/epistemológico de que a construção da etnografia é um ato igualmente político, quis antes mostrar o esplendor e a complexidade cultural dos Karajá do que afundar a tecla do tema da bebida e do caos tão registrados nos relatórios do SPI e FUNAI. Assumi a autoria do texto. Em grande parte dele, usei a primeira pessoa. Produzi uma dissertação de mestrado publicada depois como Hetohoky - um rito Karajá (Lima Filho, 1991). Para tal, mergulhei na bibliografia dos rituais e do encontro etnográfico com Gregory Bateson, Victor Turner, Julio C. Melatti, Arnod van Gennep, Stanley Tambiah, Karindo Kondo e nas etnografias de Eduardo Viveiros de Castro, Antony Segger, Alcida Rita Ramos, David Maybury-Lewis, Heloisa Fenelon, Roberto DaMatta, Terence Turner, William Crocker entre outros. E ainda as etnografias específicas sobre os Karajá, uma vez que eu havia feito um levantamento bibliográfico em bibliotecas e arquivos (não havia internete nessa época), chegando a um grande número de referências bibliográficas levantadas e depois fichadas. Para essa pesquisa e livro, concorri e obtive sucesso por meio de seleção pública a recursos tanto do Núcleo de Pesquisas Comparadas da UnB (Fundação Ford) quanto da ANPOCS/Fundação Ford. Hoje, os Karajá usam meu livro para se lembrar das plantas rituais, da ordem dos eventos rituais, como já me disseram tantas vezes, já que os grandes chefes rituais se foram ou já não se lembram tanto devido às suas condições de senilidade. O uso do meu livro pelos Karajá me mostrou uma dimensão política, acadêmica e pessoal de relevância, fato que encontra ressonâncias nas reflexões de Alba Zaluar (1997) no artigo "Teoria e prática do trabalho de campo" sobre o método e a pesquisa de campo etnográfico.

Dessa primeira empreita, um ritual de iniciação antropológica, além do livro, Hetohoky: um rito Karajá, produzi um pequeno documentário sobre o ritual com imagens 
em movimento, um artigo sobre gênero intitulado A Contribuição da Etnografia Karajá aos estudos do Gênero, (Lima Filho, 1999) um artigo em parceira com a socióloga Deis Siqueira (Lima Filho e Siqueira, 1999) que recebeu o nome Navegando no Araguaia e por fim, $a$ organização, em conjunto com Maria Eugênia Brandão Alvarenga Nunes, do livro Cerâmica Karajá e outras notas etnográficas, (Lima Filho e Nunes, 1982) sobre as bonecas karajá, a partir das notas de campo de Mário Ferreira Simões, que esteve entre eles (19541956).

Apresentei trabalhos em congressos de Antropologia e de Arqueologia. Em 1982 ingressei na Associação Brasileira de Antropologia, em Belo Horizonte.

A experiência de campo trouxe maturidade, agora ao recém-iniciado antropólogo, que buscava conciliar o rigor acadêmico da pesquisa empírica desde os tempos da Geologia e da Arqueologia com a concepção e a prática do método etnográfico. Aqui devo dizer que fui marcado pelo método estruturalista, que me fazia ver sentidos nos dados classificatórios dos Karajá e sua cosmovisão por meio das transcrições e análise dos mitos e suas correlações com o ritual do Hetohoky. No curso "Mitológicas" que fiz na UnB, com Julio Cezar Melatti, exercitei a paciência de ler inúmeros mitos analisados por Claude LéviStrauss. Buscava, no estruturalismo enquanto método, a significação de termos que têm uma relação entre si, mas não paralisava diante da aridez da estrutura com a pretensão de revelar, de forma quase autônoma e universal, a cultura. Lancei mão do estruturalismo para tentar compreender como e o quê os Karajá pensavam. Era uma porta de entrada. Contudo, estava também interessado nas suas ações enquanto texto que devia ser lido a partir da realidade de um contato interétnico, quando categorias culturais eram intercambiadas, deixadas ou assumidas. Processo que pode ser figurado pelas relações continuidade/mudança; resistência/acomodação, estrutura/evento; cultura/história e local/universal.

Somando a isso e tendo como referência a ética e a noção política do fazer antropológico inerentes a esse próprio fazer, compreendi, na prática do meu ofício de antropólogo, o sentido da reflexão de Alcida Ramos de que fazer Antropologia no Brasil é fazer política. Eu ia tecendo com os conhecimentos que se acumulavam, com o suporte teórico que adquiria, a consciência profissional que exigiria de mim resistência, paciência e firmeza nos propósitos de lapidar a minha prática e ética profissional. Explico.

Em 1991, produzi um laudo antropológico sobre as terras dos Karajá de Aruanã que serviu como documento base para que as lideranças indígenas entrassem com uma representação no Ministério Público Federal em Goiás em desfavor da FUNAI, no sentido de tomar providências para iniciar o processo de identificação, demarcação e registro das 
terras indígenas dos Karajá de Aruanã. Disso escrevi o artigo "Quando os mortos não são os nossos!”, publicado no principal jornal de Goiânia em 2001, assim como um artigo acadêmico intitulado "Entre a paixão e a técnica: a incomensurabilidade de ser antropólogo - a experiência da demarcação das terras dos Karaja de Aruanã” (Lima Filho, 2005) publicado em livro organizado por Antonio Carlos de Souza Lima e Henyo Andrade como resultado de um GT sobre Laudos Antropológicos na 23 ${ }^{\mathrm{a}} \mathrm{RBA}$, em Gramado (RS). Percebi, que neste diálogo entre o campo jurídico e o campo da Antropologia, havia duas naturezas de discursos e narrativas, um novo campo etnográfico. Era preciso sintonizar os dados etnográficos, identificar as polissemias dos discursos dos vários atores sociais envolvidos, na perspectiva mesmo de Mikhail Bakhtin, das formações discursivas foucaultianas e da demarcação de campos bourdieusianos ligados ao sistema e ao poder. Eu não falava para a academia. Falava para o positivista mundo do Direito com suas lógicas, decretos, argumentos e contra-argumentos. Um desafio, sem dúvida. Entre o meu mundo e dos Karajá, internalizei o depoimento de Claude Lévi-Strauss (1986) em Tristes Trópicos: o antropólogo está sempre entre dois mundos - o seu próprio e o do Outro - com quem vivenciou e negociou a experiência etnográfica. Uma matriz intelectual clivada.

Decidi continuar meus estudos na UnB. Estava interessado no tema da representação do contato, cosmologia e história. Feitas as disciplinas obrigatórias do Doutorado, eu estava também particularmente interessado na noção de região, nação e fronteira, na esteira da reflexão acadêmica de Benedict Anderson e sua noção de “comunidade imaginada", Eric H. Hobsbawm, Eric Wolf, M. Guibernau, E. Gellner, etc. A minha experiência etnográfica com os Karajá na Ilha do Bananal trouxera dados recorrentes sobre a Marcha para o Oeste, a Fundação Brasil Central e o Hotel JK. Eram eventos e instituições introjetados pelos Karajá e cheios de sentidos nas narrativas a respeito do contato interétnico.

Após a etapa de estudos na UnB, ganhei uma bolsa de doutorado sanduíche da Fulbrigth e da Capes para fazer pesquisas e estudos no Departamento de Antropologia da Harvard University que dispunha do Peabody Museum e da qualificada Tozzer Library, especializada em Antropologia. Na Harvard, tive como tutor o professor David MayburyLewis. Uma vez cursado o primeiro semestre, resolvi cursar o quarter no Departamento de Antropologia da Universidade de Chicago, tendo como anfitrião Terence Turner, com quem fiz um curso sobre os Kaiapó. Em Chicago, fiz um curso sobre "Cultura” com Marshall Sahlins que, na época, estava travando um ríspido debate com Gananath Obeyesekere sobre a racionalidade havaiana. Fiz ainda um curso sobre "Memória" com Manuela Carneiro. Os 
cursos da Manuela Carneiro e de Marshall Sahlins foram fundamentais para complementar minha formação e embasar minhas questões etnográficas. Com Marshall Sahlins levantei bibliografias sobre narrativas míticas e experiências históricas e, com Manuela Carneiro tive acesso a uma bibliografia sobre a construção social da memória. Conheci os textos de Frances Yates e, de modo especial, Maurice Halbwachs, que abriram outros horizontes teóricos. Desde o meu campo entre os Karajá, havia registrado uma espécie de memória afetiva construída pelas mulheres ao narrar a história de seus entes queridos masculinos pelo choro ritual. Com o curso de Chicago, estavam delineadas as minhas questões etnográficas a serem respondidas entre os Karajá, tendo como foco a Fundação Brasil Central.

De volta ao Brasil, percebi que uma distância existia entre um projeto ideal etnográfico e a realidade empírica exposta na pesquisa de campo. Encontrei os Karajá de Santa Izabel quase que numa situação de anomia durkheiminiana. Uma grande histeria coletiva entre as crianças se processava. Jovens de 10 a 12 anos tinham súbidos "ataques de loucura": queimavam casas, se automutilavam, tentavam suicídios e um grande sofrimento se instalara. Aspectos de segredos xamânicos e de foro íntimos do mundo dos homens eram expostos em reuniões administrativas da FUNAI e FUNASA em busca de solução com psiquiatras, antropólogos e, inclusive, com a vinda de um xamã do Xingu. Vi a aldeia em que vivera exposta e sofrida. Percebi que não era momento de perguntas e projetos etnográficos que tivessem o xamanismo como objeto principal. Não naquele momento. Vivíamos os vaivéns dos planos econômicos. Não havia financiamento de pesquisa na UnB. A bolsa de estudos estava desvalorizada e o campo na Ilha do Bananal se tornava inviável, já que o cacique me cobrava ganhos financeiros caso eu iniciasse a pesquisa. Aprendi com Evans-Pritchard que o objeto do antropólogo e o estudo dos seres humanos e que este trabalho envolve toda a nossa personalidade, cabeça e coração.

Diante da situação encontrada, os Karajá e eu fizemos uma pausa. Construída tacitamente às margens do Araguaia. De forma silenciosa, sussurrada, triste. Agora expressa no papel.

Portanto, o campo, o encontro etnográfico me empurraram para outra direção. $\mathrm{O}$ foco continuava sendo a Fundação Brasil Central, mas decidi trilhar pelo viés do ritual e da performance com outros atores sociais, embora os Karajá estivessem igualmente presentes.

Fui estudar a Festa do Pioneiro da Marcha para o Oeste, que acontece todos os anos em Nova Xantina (MT) para celebrar a chegada da Expedição Roncador Xingu. Assim, ao partir para o campo nas cidades que compõem o Médio Araguaia, como Aragarças (GO), Barra do Garças (MT), Nova Xavantina (MT), São Félix do Araguaia(MT) e Luciara (MT), 
encontrei uma situação etnográfica de guardiães das memórias por meio de atores sociais que guardavam consigo arquivos de documentos, fotografias, filmes, diários e objetos, evidenciando um processo nativo de reprodução social da memória via construção de museus locais/regionais articulados por pessoas que participaram da Expedição Roncador Xingu e trabalhadores da Fundação Brasil Central e SUDECO. Igualmente, historiadores locais, a maioria outsiders, usavam dessa memória dos estabelecidos, para usar categorias de Elias como "memória por empréstimo" para a construção de sua próprias identidades locais, regionais e, principalmente, do processo de construção de personas (no sentido maussiniano) políticas e uso de poder, como senadores, prefeitos, vereadores e secretários municipais. Foram feitas aproximadamente 100 fitas gravadas. A minha estratégia teórica foi conceber a Marcha para o Oeste como narrativa mítica, retomando a idéia de Neide Esterci (1972) sobre O Mito da Democracia no País das Bandeiras. Percebi que esse grande movimento de construção da nação brasileira que caminhava para dentro, como escreveu Candice Vidal e Souza (1997), produziu encantos, mas também desencantos. A memória coletiva, construída por dentro, demarcava tempos e espaços qualitativos a operacionalizar uma eficácia simbólica que explodia os eventos nas estruturas míticas construídas pelos pioneiros, que buscavam dar sentidos identitários às suas vidas depois da extinção da FBC e da grande crise estrutural que se alojou na região do Médio Araguaia, findos os tempos de Vargas e Kubitschek. Os arquivos, objetos, imagens fixas e em movimento eram referências culturais materiais como um estojo de coisas que produziam ressonâncias patrimoniais. Um estoque simbólico, dinâmico e sempre disponível para ser explorado de acordo com as circunstâncias do tempo presente, a (re) alimentar identidades individuais e coletivas no Médio Araguaia. Nesse momento a vida me deu de presente o encontro com a professora Cornelia Eckert $(1993,1994)$ que me ensinou sobre Henry Begson, Bachelard, Eclea Bosi e sua etnografias da festa e da memória em arrio dos ratos e Le Comb na França. Com essa pesquisa, pude compreender melhor o quadro histórico e cultural e as multifaces da Fronteira que atravessa o território dos Karajá. Muito havia sido escrito sobre a Marcha para o Oeste, mas quase nada havia sido registrado e interpretado do ponto de vista de quem de fato marchou para o Oeste. Defendi minha tese em 1996, publicada no ano de 2001 sob o título $O$ (des) encanto do Oeste e apresentei os resultados da pesquisa em congressos nacionais e em dois internacionais de história oral: um em Ávila (Espanha) e outro em Anchorage/Alasca (EUA) financiados pela CAPES e CNPq. Publiquei (Lima Filho, 2000) um dos capítulos do livro na Revista Horizontes Antropológicos (UFRGS) com o título Aragarças: a cidade encantada no sertão de Goiás e um artigo 
numa coletânea sobre Memória e História Oral organizado pelo Departamento de História da UnB que recebeu o nome de "Memória e Identidade Social no Médio Araguaia."

Elaborei um projeto de mestrado profissional que explorasse o diálogo da pesquisa arqueológica, acervo audiovisual, etnologia indígena, etno-história e estudos ambientais. A CAPES recomendou o mestrado em 2001, ano em que se iniciou a primeira turma. Ao mesmo tempo em que fazia parte do corpo docente do mestrado, fiz parte dos editores do primeiro número da revista Habitus, concebida para ser uma referência na publicação de estudos do patrimônio na perspectiva da Antropologia, Arqueologia e Meio Ambiente. Igualmente me preparava para assumir disciplinas do mestrado na área de Antropologia e Patrimônio Cultural. Formou-se um grupo de docentes de excelência no programa, reforçado pela contratação dos professores Roque de Barros Laraia, Klaas Woortmann, e professores convidados, como Ellen F. Woortmann, Nesse período, Gustavo Lins Ribeiro me convidou para a Diretoria da ABA como Tesoureiro Adjunto. O Patrimônio entrava assim na pauta como reflexão acadêmica pelov viés da antropologia.

Enquanto a administração do IGPA tomava minha atenção, assim com as aulas e orientações nos dois mestrados, participei da equipe do projeto de resgate do patrimônio cultural da Aproveitamento Múltiplo do Rio Manso (APM Manso), Chapada dos Guimarães (MT) por três anos, financiado por FURNAS S.A. Realizei etapas de campo sistemáticas antes, durante e depois do enchimento do lago. Os princípio conceitual era o tema da mudança e da continuidade, dando atenção aos rituais, às relações de compadrio, à territorialidade, à cultura material, ao patrimônio imaterial e ao processo de impactos ambientais e sociais. Fiquei responsável pelos estudos de uma comunidade rural diretamente afetada pelo empreendimento e que realizava, há anos, uma festa de São João Batista. Elaborei e coordenei o projeto de pesquisa "Memória, Festa e $(\mathrm{Re})$ territorialização de uma comunidade camponesa atingida pela hidrelétrica APM Manso (MT)” em 2001/2003. Foquei os meus registros etnográficos naquela comunidade. Dessa experiência de pesquisa de contrato, publiquei o capítulo "Entre dois tempos e uma hidrelétrica: festa e território de comunidade impactada pela hidrelétrica APM Manso (MT) (Lima Filho, 2006) do livro História e Antropologia no Vale do rio Manso (MT) e apresentei os resultados na V Reunião de Antropologia do Mercosul de Florianópolis, num GT coordenado pelo antropólogo Sílvio Coelho dos Santos. Durante a pesquisa, comecei a experimentar uma metodologia em que os entrevistados desenhavam livremente os lugares, ambientes, pessoas, símbolos e festas. Isso foi muito útil para compreender, por exemplo, a noção de espaço e de lugar, especialmente aqueles associados aos rituais, como o giro da bandeira, seus personagens, os 
sítios camponeses, as relações de compadrio, a relação terra/água, os santos e a bandeira. Após o (re)assentamento das famílias, assistia a essa lógica nativa ser destruída, à festa acabada e à segmentação do grupo social, a despeito de carta oficial preventiva destinada a FURNAS S.A.

Assumi a coordenação do Mestrado Profissional em Gestão do Patrimônio Cultural da UCG por dois mandatos e o , coordenei o projeto "Antropologia na Cidade: memória, identidade e referências culturais sobre o núcleo pioneiro de Goiânia", Tomamos o rito do tombamento do polígono histórico da cidade de Goiânia e seu conjunto de 22 elementos edificados tidos como representantes excepcionais do art déco como fato social, o que nos motivou a pesquisar sobre a produção simbólica e os significados das narrativas a espelhar as representações sociais da cidade por meio dos estudos da tradição, memória, identidade social relacionados ao tema do patrimônio cultural a informar sobre as referências culturais da cidade. A cidade de Goiás havia sido contemplada com o título de patrimônio da humanidade pela UNESCO e o IPHAN iniciava um processo de documentação para propor o tombamento federal do conjunto art déco de Goiânia. Foi quando publiquei o artigo o "O Futuro do Passado da Cidade de Goiás: gestão, memória e identidade”. (Lima Filho, 2003). Orientei duas dissertações de mestrado que utilizaram desenhos sobre a cidade: Wilton de Araújo Medeiros defendeu a dissertação "Patrimônio, Memória e Gestão: uma nova imagem de Goiânia", quando trabalhou com as memória dos velhos pioneiros por meio de seus desenhos e narrativas, enquanto Ronaldo Rosa dos Santos Junior defendeu a dissertação "Goiânia Patrimônio Cultural e as Crianças: uma etnografia da cidade". Ronaldo partiu do principio antropológico da criança como sujeito social e coletou centenas de desenhos entres escolas de periferia e de classe média de Goiânia.

Como produção final, escrevi o artigo para a revista Ilha (UFSC) "Goiânia, uma cidade patrimonial?"; um artigo juntamente com o antropólogo Flávio Leonel da Silveira Abreu (UFPA), publicado na revista Horizontes Antropológicos (UFRGS) (Silveira e Lima Filho, 2005) com o título "Por uma antropologia do objeto documental: entre a 'alma nas coisas' e a coisificação do objeto". Em forma de capítulos de livros, publiquei "A cidade como objeto: ressonâncias patrimoniais (Lima Filho 2007), no livro Museus, Coleções e Patrimônios: narrativas polifônicas, organizado por Regina Abreu, Mário Chagas e Myriam Sepúlveda dos Santos e o capítulo "Entre Formas e Tempos: Goiânia na perspectiva patrimonial" no livro Antropologia e Patrimônio Cultural - diálogos e desafios contemporâneos, (Lima Filho, 2007) organizado por Cornelia Eckert, Jane Beltrão e por mim. Apresentei trabalhos em congressos nacionais e organizei, juntamente com a 
historiadora Laís Aparecida Machado, o livro Formas e Tempo da Cidade (Lima Filho e Machado, 2007), quando escrevi a Introdução "Múltiplos Olhares sobre Goiânia” e um dos capítulos do livro: "Trilhas Patrimoniais de Goiânia". Esse projeto possibilitou outra parceria acadêmica com o Departamento de Antropologia da Universidade Federal do Rio Grande do Sul, junto ao NAVISUAL, quando as antropólogas Cornelia Eckert e Ana Luiza Carvalho da Rocha tornaram-se consultoras do projeto, escrevendo a apresentação do referido livro. Um site do projeto foi elaborado e disponibilizou as produções de textos, seminários, notas e fotos.

Depois elaborei dois projetos de pesquisa. Um deles, o projeto "A Cidade Patrimonial: os tecidos Sociais em Ouro Preto (MG)" (2007), foi aprovado pelo CNPq. Nesse momento, Ana Luiza Carvalho da Rocha passa a ser consultora juntamente com Cornelia. Realizei 6 etapas de campo na cidade de Ouro Preto com a participação de alunos da graduação e um mestrando e a continuação da parceria do NAVISUAL do PPGAS da UFRGS. Aplicamos 400 questionários entre os estudantes das Repúblicas de Ouro Preto, várias entrevistas gravadas e em processo de decupação e ainda 22 horas de gravação com câmara de cinema, à feitura de relatórios técnicos, artigos para publicação, um livro e um documentário.

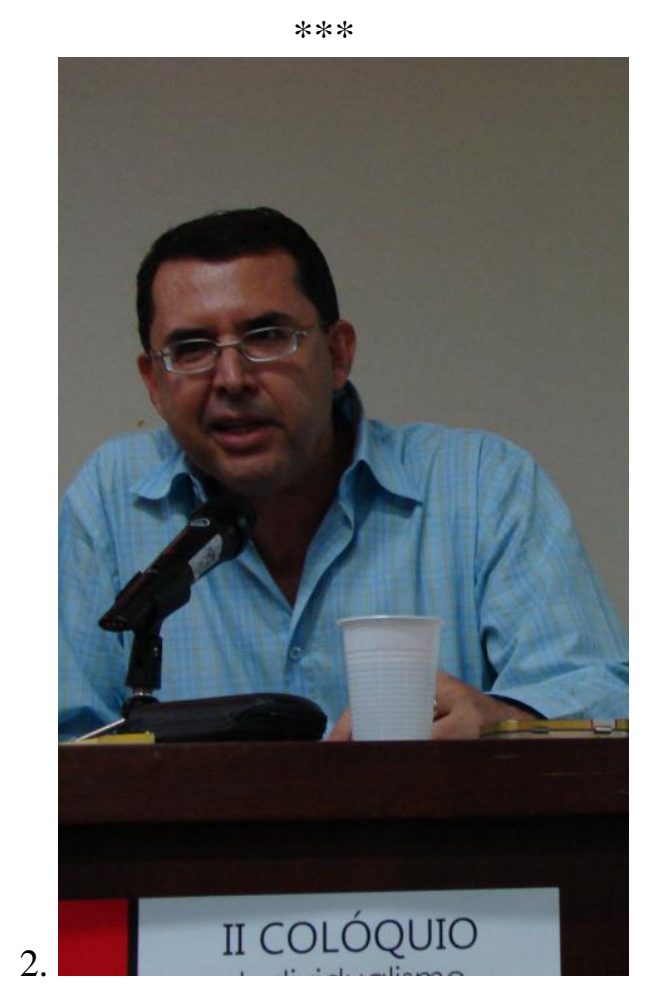

Prof. Manuel Ferreira Lima Filho. Foto de 03 dezembro 2010. Conferência no II Colóquio Individualismo, Sociabilidade e Memória. Sala Pantheon IFCH UFRGS. Acervo BIEV PPGAS IFCH UFRGS. 
Para o pós-doutorado elaborei o projeto "Cultural Heritage and National identity in Brazil and United States of America: artifacts, museums collection and Ethnic/Social Memory in Williamsburg (USA) and Ouro Preto (Brazil)", que foi aprovado pela CAPES e pela Rockefeller Library da Colonial Williamsburg Foundation, com bolsa de estudos e pesquisa e publiquei o artigo Cidades Patrimoniais e Identidades Nacionais: questões antropológicas na perspectiva comparativa entre o Brasil e os Estados Unidos no livro "Trilhas Patrimoniais" organizado em 2006 por mim e Márcia Bezerra.

Em 2007, viajei para os Estados Unidos e me concentrei na pesquisa entre estudantes do College of William and Mary, na cidade Living Museum de Colonial Williamsburg e na comunidade afrodescendente Mont Ararat Baptist Church localizada na borda do complexo museológico e turístico de Williamsburg. Aproveitei também da Rockfeller Library, especializada biblioteca sobre a história norte americana, e de modo especial, sobre a escravidão e o patrimônio cultural. Nesse momento, tive a oportunidade de seguir o curso "Exploring American Past", ministrado pelos antropólogos Richard Price e Sally Price, assim como, o curso "Museuns and Representations of Slavery" ministrado pela arqueóloga Yonne Edward-Ingrams, que estuda a arqueologia da escravidão em Williamsburg, Virginia. Os resultado esta publicado no livro organizado por Flávio Leonel sobre paisagens culturais.

O desenvolvimento dos projetos sobre Goiânia, Ouro Preto e Williamsburg me permitiu conectar três domínios de análise que têm relações com o modo antropológico de produzir conhecimento. O primeiro é a questão da nação. Enquanto associado à identidade, um tema clássico da disciplina e apesar de ter produzido vários debates e novos pontos de vistas desde a formulação de Anderson sobre "comunidade imaginada", Schneider, entretanto, chama a atenção de que a categoria nação, enquanto categoria analítica, pode ser problemática empiricamente quando contrastadas, com as categorias analíticas da tradição antropológica. Enquanto representação discursiva, ela não é necessariamente reflexo das práticas culturais para desempenhar aquilo que ele chama de princípio estruturante da percepção e da interpretação. Da mesma maneira, Lavalle aponta que certos temas, como a questão racial, a moral pública, a identidade e a integração nacional, enquanto temas construtivos do estado nacional brasileiro, não definem necessariamente a singularidade do pensamento local. Então, se a nação é boa para pensar, deve-se, todavia, ter o cuidado metodológico de contextualizar que tipo de conhecimento estamos absorvendo de uma categoria tão ampla. Visto isso, busquei uma mediação a partir de um contexto empírico mais definido. Optei pelo recorte temático de "cidade patrimonial", categoria que passei a denominar como locus possível de mediação de encontro entre a idéia de nação, região e 
eventos históricos e culturais que transcorrem no espaço concreto e social da cidade. Goiânia, fruto da ideologia da Marcha para o Oeste, acabava de se tornar "cidade patrimonial" pelo tombamento do seu polígono histórico pelo IPHAN e um movimento político e intelectual quisera reduzir a identidade da cidade ao estilo art decó. Ouro Preto, palco de dramas e tramas históricos culturais sobre a construção do Estado-Nação brasileiro, não tinha sido objeto de pesquisas antropológicas. A colonial Williamsburg foi escolhida por Rockfeller Jr. e o bispo da cidade, que também era o reitor da Universidade, para, desde 1924, ritualizar a construção do Estado-Nação norte-americano, tendo como estratégia as réplicas das casas setecentistas, a noção de "autenticidade" baseada em evidências arqueológicas, as (re) encenações de atores e turistas, utilizando uma parada no ano de 1775 , tempo da Revolução Americana. Nesse sentido, equacionei a cidade como um "objeto cultural", que produz ressonâncias, que se torna mediadora temporal (passado, presente e futuro) e evoca memórias subjetivas e coletivas. A materialidade (Menezes,1998) está marcada pela simples durabilidade do objeto e, por ser assim, ele costuma ultrapassar a vida de seus produtores e usuários originais e torna-se apto a expressar o passado de forma profunda e sensorialmente convincente. Mas a materialidade dos objetos está intrinsecamente associada à sua extensão imaterial ou intangibilidade de patrimônio. $\mathrm{O}$ objeto, apesar da nossa razão, teria um caráter antropomórfico, "pensando sobre nós”, como arriscaria Henri Jeudy.

Concluímos então que, se as práticas operacionais ou gerenciais ou dados empíricos não têm correspondência com o discurso produzido da nação, isso não inviabiliza a sua invenção e operacionalidade simbólica pelos Estado e gestores culturais. Há, então, uma intertextualidade, cujos fios narrativos arranjam as contradições na trama que desenha a cidade patrimonial. Tempos monumentais distintos para o antropólogo Michael Herzfeld. Diferenciam-se o tempo monumental do Estado-Nação e o tempo monumental dos "nativos". Assim, a cidade, enquanto objeto cultural, é alvo de tensões e oferece boas pistas de pesquisa antropológica. Para tal, decidi, nos três contextos etnográficos, ouvir os velhos, as crianças, os jovens e os afrodescentes, no caso em Williamsburg, por meio da comunidade Mont Ararat Baptist Church e, em Ouro Preto, por meio da Irmandade dos Pretos de Nossa Senhora do Rosário e de Santa Ifigênia, fundada em 1727. Personagens míticos, como a Santa Negra (Santa Ifigênia) e o Rei Negro (Chico Rei), são centrais nas narrativas da Irmandade da comunidade/bairro que habita os arredores da Igreja e da cidade de Ouro Preto e que vivenciam um processo de construção de um museu afro-brasileiro ao lado da igreja barroca da Irmandade (Lima Filho,2009). Dialogando com José Reginaldo 
Santos Gonçalves, comungo que, na perspectiva da subjetividade, o tema do patrimônio instaura um tipo de "mediação" entre a "cultura herdada" e "a cultura reconstruída". O sujeito interage com os objetos patrimoniais, estabelece uma relação consigo mesmo e com a alteridade.

Ainda do ponto de vista conceitual/metodológico, meus estudos estão igualmente centrados no tema da representação social e cultural, privilegiando o saber local já ponderado por Franz Boas desde os tempos clássicos da disciplina e problematizado por Clifford Geertz, e, sempre, desde os tempos do mestrado, ancorado pelo método etnográfico, pois acredito como Ellen F. Woortmann que o método etnográfico como ‘trabalho de campo' e como gênero textual dá o caráter distintivo da Antropologia. Mas a pesquisa de campo num contexto urbano, aparentemente mais fácil que as pesquisas etnológicas, se apresentou para mim, na realidade, como um grande desafio, naquilo que Gilberto Velho chamou de "o desafio da proximidade", cuja empreita principal, como escreveu Ruben Oliven, é interpretar a sua própria cultura e questionar pressupostos muitas vezes tidos como inquestionáveis, ou seja, trata-se de conhecer nossos rituais, nossos símbolos, nosso sistema de parentesco, nosso sistema de trocas. Vindo de uma experiência radical de encontro com a alteridade por meio da pesquisa de campo com os Karajá, a pesquisa na cidade de fato era um desafio metodológico e teórico. Ótima oportunidade para concatenar também a minha experiência etnográfica com as formações de cidades no Médio Araguaia no doutorado e, de modo especial, a construção de Aragarças (GO) que foi objeto de publicação de um artigo na revista Horizontes Antropológicos (UFRGS) e que recebeu o nome de "Aragarças: a cidade encantada no sertão de Goiás".

Era preciso estranhar as próprias narrativas de cidade, fazer a radicalidade da proposta da pesquisa de campo, também no contexto urbano, ir à raiz dos fenômenos estudados e perceber de que modo a cultura reflete e medeia as contradições de uma sociedade complexa. Goiânia, Ouro Preto e Williamsburg me permitiram conhecer e aprender a fazer uma Antropologia na cidade. Mais uma etapa de conhecimento antropológico a lapidar minha formação, reflexões e sínteses.

Finalmente, após os anos de estudos, orientação e docência sobre o patrimônio cultural brasileiro e diante do tema crescente sobre o patrimônio imaterial, escrevi um artigo que acaba de ser publicado na Revista de Antropologia da USP o nome de "Da Matéria ao Sujeito: inquietação patrimonial brasileira" expõem a minha reflexão sobre a trajetória do patrimônio cultural no Brasil, sob a ótica da noção antropológica de cultura. 
A minha trajetória acadêmica sempre foi marcada pela minha experiência de campo entre os Karajá. Como em estado de latência bachelardiana, ela sempre esteve lá, a provocar insigts. Desenvolvi em 2010- 2011 em parceria com as antropólogas Nei Clara de Lima, Telma Camargo da Silva e Rosani Moreira Leitão o projeto "Bonecas karajá: arte, memória e identidade indígena no Araguaia" com o intuito de elaborar um dossiê para o IPHAN a fim de subsidiar o registro do saber fazer as bonecas Karajá com patrimônio Imaterial brasileiro. Deste projeto resultou também o filme Ritxokò sob a direção do Antonio Neto. Esse projeto induziu uma viagem a campo nas aldeias Karajá de Aruanã e Santa Izabel do Morro, após um logo período de minha ausência entre eles.

Por fim atualmente, sou professor e pesquisador da Universidade Federal de Goiás e desenvolvo desde 2010, com fomento do CNPq, o projeto de pesquisa "Realeza Negra: Memória, Arquivo e Representações Museais da Irmandade de Pretos de Santa Ifigênia Ouro Preto $(\mathrm{MG}) "$ que já produziu o artigo sobre "Espelhos patrimoniais em Ouro Preto: museus e passado afro-brasileiro" (2010).

Tenho como inspiração a pesquisa de campo, que me leva sempre a buscar novos diálogos teóricos e desafiantes. Na busca do olhar, ouvir e escrever lembra-me o mestre Roberto Cardoso de Oliveira de fazer da experiência antropológica objeto de interesse que transcende a disciplina. Enfim, voltando por onde comecei: um fecundo diálogo interdisciplinar.

\section{Referências}

ANDERSON, Benectid. Imagined Communities. Londo: Verso, 1991.

ECKERT, Cornelia. "A saudade em festa e a ética da lembrança". In: Revista Estudos Feministas, v.5, n.1. Florianópolis: UFSC, 1997.

ECKERT, Cornelia. "Memória e Identidade: Ritmos e ressonâncias de duração de uma comunidade de trabalho: mineiros de carvão (La grand-combe, França)". In: Cadernos de Antropologia. Porto Alegre: PPGAS/UFRGS, 1993.

ESTERCI, Neide. O mito da democracia no país das bandeiras. Dissertação de Mestrado. Rio de Janeiro: UFRJ/Museu Nacional, 1972.

LEVI-STRAUSS, Claude. Tristes Trópicos. Lisboa: Edições 70, 1896.

LIMA FILHO, Manuel Ferreira e BRANDÃO, Eugênia A.N. Cerâmica Karajá e outras notas etnográficas de Mário Ferreira Simões. Goiânia: Editora da UCG, 1986.

LIMA FILHO, Manuel Ferreira. $O$ (des) encanto do Oeste. Goiânia: Editora da UCG, 2001. LIMA FILHO, Manuel Ferreira; SIQUEIRA, D. "Navegando no Araguaia". In: Revista Estudos. Goiânia: Editora da UCG, 1999.

LIMA FILHO, Manuel Ferreira. "Espelhos patrimoniais em Ouro Preto: museus e passado afro-brasileiro". In: Revista Tomo, v.1, n.16. Sergipe: UFS, 2010. p.197 - 220.

LIMA FILHO, Manuel Ferreira. "A Contribuição da Etnografia Karajá aos estudos do 
Gênero". In: Cadernos de Área, Estudos de Gênero, v. 9. Goiânia: Editora da UFG, 1999. p.83 - 102.

LIMA FILHO, Manuel Ferreira. "Aragarças: a cidade encantada no sertão de Goiás". In: Horizontes Antropológicos, v.13. Porto Alegre: PPGAS/ UFRGS, 2000. p.65 - 87.

LIMA FILHO, Manuel Ferreira. "Entre a paixão e a técnica: reflexões sobre o processo de identificação e demarcação das terras dos Karajá de Aruanã (GO)". In: Antropologia e Identificação, v.1. Rio de Janeiro: Contracapa, 2005. p. 323-353.

LIMA FILHO, Manuel Ferreira. "Entre dois tempos e uma hidrelétrica: festa e território de comunidade impactada pela hidrelétrica APM-Manso (MT)" In: História e Antropologia no Vale do Rio Manso (MT) ed. Goiânia : UCG, 2006, v.1, p. 265-287.

LIMA FILHO, Manuel Ferreira. Hetohoky - um rito Karajá. Goiânia: Editora da UCG, 1991.

LIMA FILHO, Manuel Ferreira; MACHADO, L. A. Formas e tempos da cidade, v.1. Goiânia: Cânone Editorial/Editora da UCG, 2007. p. 280.

LIMA FILHO, Manuel Ferreira; BEZERRA, M. A. Os Caminhos do Patrimônio no Brasil, v.1. Goiânia: Editora Alternativa, 2006. p.193.

LIMA FILHO, Manuel Ferreira. "Cidades Patrimoniais e Identidades Nacionais: questões antropológicas na perspectiva comparativa entre o Brasil e os Estados Unidos". In: Os Caminhos do Patrimônio no Brasil. Goiânia: Editora Alternativa, 2006. p. 17-42.

LIMA FILHO, Manuel Ferreira; BRANDÃO, M. E. A. N. Cerâmica Karajá e outras notas etnográficas, v.1. Goiânia: UCG, 1982. p.50.

LIMA FILHO, Manuel Ferreira. "O futuro do passado da cidade de Goiás: gestão, memória e Identidade". In: Revista Habitus, v.2. Goiânia: UCG, 2003. p.32 - 43.

LIMA FILHO, Manuel Ferreira. "Quando os Mortos não são os Nossos". In: Jornal $O$ Popular. Goiânia: J. Câmara \& Irmãos S.A., 2001.

LIMA FILHO, Manuel Ferreira. "Paisagens Patrimoniais e o Jogo do Tempo em Williamsburg (EUA) e Ouro Preto (Brasil)". In: Paisagem e cultura: dinâmicas do patrimônio e da memória na atualidade. Belém: Editora da UFPa, 2009. p. 45-62.

LIMA FILHO, Manuel Ferreira. "Entre Formas e Tempos: Goiânia na Perspectiva do Patrimônio". In: LIMA FILHO, Manuel Ferreira; ECKERT, Cornelia; BELTRÃO,

Jane (Orgs.). Antropologia e patrimônio cultural: diálogos e desafios contemporâneos. Blumenau: Nova Letra, 2007. p. 221-236

MALINOWSKI, Bronislaw. Os Argonautas do Pacífico Ocidental. São Paulo: Abril Cultural, 1978.

MAYBURY-LEWIS, David. “Introduction”. In: Dialectical Societies. Cambridge: Harvard University Press, 1979.

MENESES, Ulpiano T. Bezerra. "Memória e Cultura Material: documentos pessoais no espaço público". In: Revista Estudos Históricos, v.11, n.21. Arquivos Pessoais. Rio de Janeiro: CPDOC/FGV, 1998.

SILVEIRA, F. L. A.; LIMA FILHO, Manuel Ferreira. "Por uma antropologia do objeto documental: entre a "alma das coisas" e a coisificação dos objetos". In: Horizontes Antropológicos, v.23. Porto Alegre: PPGAS/ UFRGS, 2005. p.37- 50.

VIDAL E SOUZA, Candice. A pátria geográfica: sertão e litoral no pensamento social brasileiro. Goiânia: Editora da UFG, 1997.

ZALUAR, Alba. "Teoria e prática do trabalho de campo: alguns problemas". In: A Aventura Antropológica. Rio de Janeiro: Ed. Paz e Terra, 1997.

Recebido em: 22/12/2010

Aprovado em: 30/03/2011 